\title{
Assessment of methods to determine soil characteristics for management and design of irrigation systems
}

\author{
Walter Valdivia-Cea ${ }^{1 *}$, Eduardo Holzapfel ${ }^{1}$, Diego Rivera ${ }^{1}$, Jerónimo Paredes ${ }^{1}$ \\ ${ }^{1}$ Department of Water Resources, College of Agricultural Engineering, University of Concepción, Av. Vicente \\ Mendez 595, 3812120 Chillán, Chile.*Corresponding author:waltervaldivia@udec.cl
}

\begin{abstract}
Irrigation system design and irrigation management require appropriate match of the soil and type of crop. In Chile, agrological reports are currently being used to determine the homogeneity of soil units and land capability classes: fruit tree production vs orchard design. Agrological studies use a number of soil characteristics, but these do not include hydrophysical properties, which are essential when zoning for irrigation. Therefore, it is necessary to establish a methodology to objectively evaluate soils, based on a quantitative analysis that includes hydrophysical parameters. In this study, different methodologies are proposed for classifying homogenous soil units based on extensive field sampling. The field data was evaluated using two methodologies: 1) the SAGUSDA Manual and 2) in situ sampling of soil's hydrophysical properties and pedotransfer models. There were differences between the methodologies regarding zoning soil properties for irrigation system design and management. The methodology based on the SAG-USDA Manual requires auxiliary data in order to provide useful maps for design and management of irrigation systems. Published pedotransfer functions should be carefully assess before their use in large-scale design, as the quality the estimations depends on the data used to derive the equations. Therefore, if field data is available, we recommend calibrating equations using well-known statistical methods such as least square. In this study, the functions obtained describe the properties of interest properly, such as the field capacity for design of micro-irrigation systems. However, predicting wilting point did not give reliable results.
\end{abstract}

Keywords: Soil hydrophysical properties, pedotransfer functions, management of irrigation systems 


\section{Introduction}

Efficient water use at farm level required adequate understanding the farm's soil properties, topography, and types of crops. In fact, understanding the spatial variability of physical soil properties is a key issue, since soil properties vary spatially within a field because of geological and pedological soil-forming factors (Iqbal et al., 2005, Dec and Dörner, 2014). Moreover, spatial variability of soil properties is also influenced by farming practices such as tillage, crop rotation and irrigation management.

Soils in Chile's Central Valley are highly variable in space, posing major problems for irrigation system design and management (Rivera et al., 2015). However, current practice for designing irrigation systems considers as main input data the crop type (Holzapfel et al., 2009), without properly incorporating soil variability. Therefore, a proper design of irrigation systems should consider, besides the crop type, other parameters linking soil and crops, such as root water extraction zone, soil depth, and soil hydrophysical properties (Holzapfel et al., 2009; Holzapfel, 2010; Holzapfel et al., 2015; Flores et al., 2010; Gooley et al., 2014). Irrigation will be efficient as long as the soil water is only extracted from the root zone. Holzapfel (2010) has indicated that the root zone from where water is extracted is a key factor in irrigation management, and should be related to soil type. This author has also reported that the main water extraction capacity by roots of some fruit trees reaches depths up to 0.6 and 0.7 meters.

Soil texture is essential to characterize soil hydrophysical properties, as it influences water-holding capacity, the soil-water characteristic curve for desorption, and hydraulic conductivity (Campbell, 1974; Van Genuchten, 1980). Bulk density (Db) is another parameter that needs to be considered as it reflects the structural conditions of the soil, manage- ment and cultural practices. Bulk Density largely determines the root growth (Cuevas et al., 2004). In addition, Selles et al. (2012) indicated that monitoring soil compaction before and after planting allows for a decrease in $\mathrm{Db}$ and soil penetration resistance and, in turn, an increase in both the macroporosity and the number of fine roots per square meter in the soil profile. Besides, $\mathrm{Db}$ relates to the degree of soil compaction and restriction to root growth (NRCS, 2008). Water-holding capacity (WHC) of the soil is associated with available soil water for possible extraction in the root zone, indicating the total amount of water that soil can hold for plant use. WHC is key for irrigation management, as it indicates the maximum amount of water to be applied, influencing both irrigation timing and frequency.

For designing irrigation systems, there must be a trade-off between soil variability, costs for delivering water and crop needs. Thus, if areas with different values of WHC -depending on soil variability- are irrigated with the same criteria of frequency and time, there will be areas with excess and others with deficit of water. Therefore, it is important to develop a methodology to define homogenous soil units, based on a quantitative analysis of hydrophysical soil parameters. This information is essential to measure and manage spatial variability, increase production efficiency and reduce environmental impact of irrigation schemes/practice. Currently in Chile, the manual developed by the Agricultural and Livestock Service (SAG) is used as a basic procedure for the description and mapping of soils. This manual (SAG, 2001), which is based on the USDA Soil Survey Manual (USDA - Soil Survey Staff, 2009), provides standards and guidelines for defining land use classes for fruit tree production. 
The study aims to assess methods of producing maps of the spatial distribution of soil properties for irrigation system design and management at the farm level. We propose an approach for defining homogenous regions based on extensive field sampling. In addition, the Saxton-Rawls method is evaluated and calibrated to estimate soil water characteristics.

\section{Materials and Methods}

Field data was used to assess the performance of two different methods to derive hydrophysical data from soil texture and define homogenous areas. Point- wise data was used to produce maps of the spatial distribution of relevant parameters for irrigation design and management, such as WHC and bulk density. To create maps, the kriging method was applied.

\subsection{Study site}

The study was conducted on a farm located in Coihueco, near Chillán in Bio Bio region (Latitude -36.622515, Longitude -71.901824, Altitude 227 m.a.s.1; (Figure 1a). The climate is Mediterranean, with dry and wet seasons. Average annual rainfall is $1,200 \mathrm{~mm}$, with a rainy season extending from April to August. According to the Chilean Natural Resources Information Center (CIREN, 1999), soils on the farm are classified as Andisol (Arrayan series, AYN), Inceptisol (Gallipavo series, GAL, and Chacayal series, CYL), and Mollisol (Mebuca series, MBU, and Talquipen series, TQP). All series are described in the Soil Survey Map of the Bio Bio Region (North Area) (Santis 2005).

\subsection{Field sampling and laboratory analyses}

Thirty-one test pits were excavated and soil samples were taken at different depths. Measurements were carried out the Water Resources Laboratory of the School of Agricultural Engineering, University of Concepción using standardized procedures (Sandoval et al., 2012). Samples from each soil horizon were packed in plastic bags to determine particle size distribution using the hydrometer method. Undisturbed samples were analyzed for bulk density and soil water content. Bulk density was measured using the natural lump method, while the water contents at $-33 \mathrm{kPa}$ (field capacity, FC) and $-1500 \mathrm{kPa}$ (wilting point, WP) were determined using the ceramic plate pressure extraction method (Sandoval et al., 2012). Water Holding Capacity (WHC) was calculated as the difference between FC and WP on a volume basis, considering soil depth (Jury et al., 1991). Field data were compared to the information provided by CIREN (1999) and the Survey Map of the Bio Bio Region (North Area) (Santis 2005). Soil variability was characterized based on the Soil Survey Manual (USDA Soil Survey Division Staff, 1993) and SAG's guidelines (2001).

\subsection{Methods for defining homogeneous soil areas}

Two methods were applied. The "Agrological method" (USDA-SAG) requires texture and soil's depth data from CIREN soil series maps (low spatial resolution 1:500,000). Data from maps was interpreted to qualitatively define homogenous units considering topography and plot boundaries. The second method (INSITU) considers field sampling of other relevant soil properties than texture, such as bulk density, infiltration rate, and water holding capacity. Then, homogenous areas were defined using ordinary kriging. Pedotransfer functions were used to provide estimates of the unknown parameters (WHC, WP) based on texture. Pedotransfer models such as the Saxton and Rawls (Saxton and Rawls,2006) could help to reduce the amount of soil analysis types. 
Field data was spatialized using kigring (Gozdowski et al., 2015). We tested the predictive skill of pedo tranfer functions when used as an auxiliary method to increase the data density.
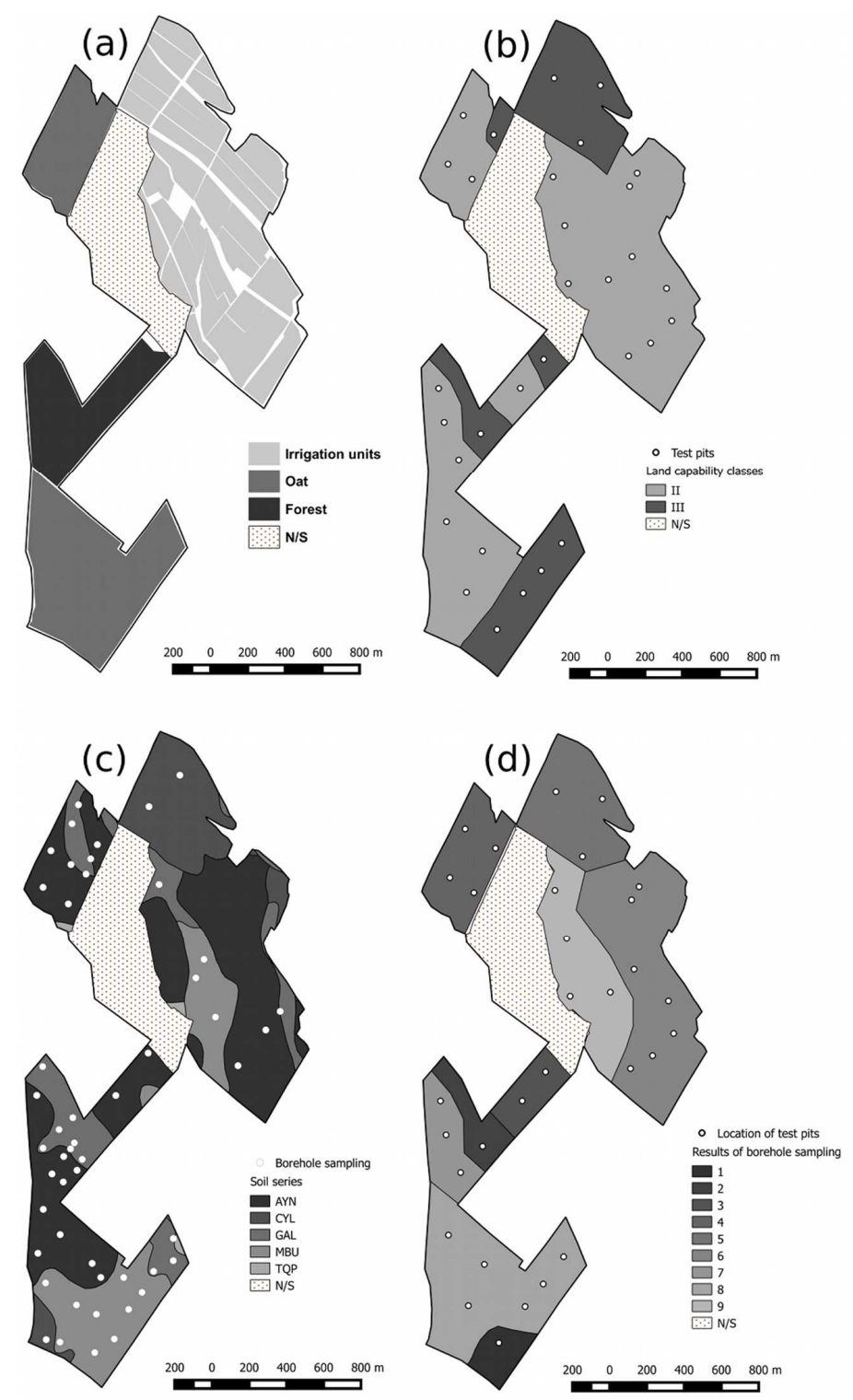

Figure 1. (a) Study site at Los Abedules Farm - Carsol Fruit S.A. Coihueco, Chile. N/S corresponds to the locations where no samples were taken. (b) Land use classes based on an agrological study according to the Soil Survey Manual and SAG's guidelines, and location of the test pits. (c) Borehole sampling points and soil series in the farm (AYN: Arrayan, CYL: Chacayal, GAL: Gallipavo, MBU: Mebuca, TQP: Talquipen,) (d) Zones identified as homogeneous (Classification $1-9$ ) 


\subsection{Pedotranfer functions}

The method proposed by Saxton and Rawls (2006) predicts the WHC by soil at a potential of $-33 \mathrm{kPa}$
(FC) and $-1500 \mathrm{kPa}(\mathrm{WP})$ from texture and Organic Matter (OM) content data.

Equations are as follows:

$$
\begin{gathered}
\theta_{1500}=\theta_{1500 t}+\left(0.14 \cdot \theta_{1500 t}-0.02\right) \\
\theta_{1500 t}=-0.24 S+0.487 C+0.0060 M+0.005(S \cdot O M)-0.013(C \cdot O M) \\
+0.068(S \cdot C)+0.031 \\
\theta_{33}=\theta_{33 t}+\left[1.283\left(\theta_{33 t}\right)^{2}-0.374\left(\theta_{33 t}\right)-0.015\right] \\
\theta_{33 t}=-0.251 S+0.195 C+0.011 O M+0.006(S \cdot O M)-0.027(C \cdot O M) \\
+0.452(S \cdot C)+0.299
\end{gathered}
$$

where $\theta_{1500}$ is the soil water content at $-1500 \mathrm{kPa}(\% \mathrm{v})$, $\theta 33$ is the soil water content at $-33 \mathrm{kPa}, \mathrm{C}$ is the fraction of clay $(\% \mathrm{w}), \mathrm{S}$ is the sand fraction $(\% \mathrm{w})$, and $\mathrm{OM}$ is the fraction of organic matter $(\% \mathrm{w})$.
Note that calculations in equations (1) and (3) are based on auxiliary variables - denoted by subscripts t- using equations (2) and (4). The general expression for a given auxiliary variable $\mathrm{Vt}$ in equations (2) and (4) are:

$$
V t=a+b S+d C+e O M+f(S \cdot O M)+g(C \cdot O M)+h(S \cdot C)
$$

where $\mathrm{S}, \mathrm{C}$, and $\mathrm{OM}$ are the predictive variables, and a, $\mathrm{b}, \mathrm{d}, \mathrm{e}, \mathrm{f}, \mathrm{g}$, and $\mathrm{h}$ are coefficients subject to calibration. The value of the coefficients is a measure of the relative weight of predictive variables on the final results. New pedotransfer relationships were fitted to field data using least squares (LS) for equations 1-4. LS methods fit a continuous function for data-pairs (independent variable, dependent variable), by minimizing the square error. The proposed model predicts soil water content at a potential of $-33 \mathrm{kPa}(\mathrm{FC})$ and $-1500 \mathrm{kPa}$ (WP). To assess the goodness-of-fit for pedotransfer functions, the coefficient of determination (R2), relative differences (RD), and the root mean square error (RMSE), against field-measured data. Even though pedotransfer functions are valuable tools for design, Wösten et al. (2001) note that the predictive skill of the functions highly depends on the calibration data set. Based on this, another pedotransfer model was developed for the soils in the study site using a quasipolynomial model based on the following variables: bulk density, percentage of clay, sand and organic material (Eq. 6 and Eq. 7). 


$$
\begin{gathered}
\theta=\left[A\left(\theta_{t}\right)^{2}+B\left(\theta_{t}\right)+C\right] \\
\theta_{t}=a+b(1 / S)+d(C)+e(O M)+f((1 / S) \cdot C)+g((1 / S) \cdot O M)+h(C \cdot O M) \\
+j\left(C^{2}\right)+k\left((1 / S)^{2}\right)+l\left(O M^{2}\right)+m\left((1 / D b)^{2}\right)+p((1 / D b) \cdot(1 / S)) \\
+q((1 / D b) \cdot C)+r((1 / D b) \cdot O M)+t((1 / D b))
\end{gathered}
$$

where $\theta$ is the water content at field capacity $\theta_{\mathrm{fc}}$ and wilting point $\theta_{\text {wp }}\left(\mathrm{m}^{3} \mathrm{~m}^{-3}\right)$ expressed as percentage, $\mathrm{S}$ and $\mathrm{C}$ are the sand and clay contents (\%) respectively, $\mathrm{OM}$ is the organic matter content $(\%)$ and $\mathrm{Db}$ is the bulk density $\left(\mathrm{g} / \mathrm{cm}^{3}\right)$. The new approach includes additional variables to the Saxton and Rawls (2006). In equation (7), predictive variables were defined after an intensive screening process.

\subsection{Spatial data}

Hydrophysical properties measured in the field were spatialized using the ordinary kriging method (Hengl, 2009). Thus, values at the locations that were not sampled in the study area were estimated. Soil maps for irrigation system design and management were discretized $\mathrm{n}$ order to define the areas with homogeneous hydrophysical properties.

Physical soil quality indices were selected as indicated by Rabbi et al. (2014). The indices are as follows: clay content is less than or equal to $40 \%$, and bulk density ranges between 0.9 and $1.2 \mathrm{~g} / \mathrm{cm}^{3}$. Regarding these indicators, USDA (2009) states that clay contents greater than or equal to $40 \%$ prevent the movement and redistribution of soil water. Regarding fine-textured soils, Reynolds et al. (2003) have indicated that bulk densities below $0.9 \mathrm{~g} / \mathrm{cm}^{3}$ prevent good contact between soil and roots, while bulk densities greater than $1.2 \mathrm{~g} / \mathrm{cm}^{3}$ stop rootlet elongation and reduce soil aeration.

Maps were compared using the coefficient of variation:

$$
C V(\%)=\frac{S D}{|\overline{\mathrm{X}}|} \cdot 100(\%)
$$

where $\mathrm{CV}$ is the coefficient of variation, $\mathrm{SD}$ is the standard deviation and $|\overline{\mathrm{X}}|$ is the mean. Thus, soil units having low values of $\mathrm{CV}$ are better than soils units showing large values for $\mathrm{CV}$.

\section{Results}

\subsection{Agrological study}

Agrological studies provide general information for crop adaptation and management, but not for irrigation system design, as the method does not include the hydrophysical properties of the soil. Figures $1 \mathrm{~b}$, 1c and $1 \mathrm{~d}$ show the result of the preliminary analysis of the soil characteristics, soil series borehole monitoring points, and areas considered as homogeneous in the study site. Soils series are: Arrayan Phase 2 (AYN-2, 152.4 ha), Mebuca Phase 2 (MBU-2, 17.4 ha), Gallipavo Phase 2 (GAL 2, $15.1 \mathrm{ha}$ ), and Chacayal Phase 2 (CYL-2, 28.4 ha). Textures ranged from fine sandy loam $(\mathrm{SaL})$ to clay loam (CL). Regarding land use, class II soils cover ca. 149 ha. This soil class has slight limitations that reduce the selection of type plants or require moderate conservation practices (soil is flat, with gentle slope, deep to moderately deep depth with good permeability and drainage). On the other hand, 
class III (moderate limitations that restrict their use such as shallow water table) covers ca. 65 ha (Figure 1c).

\subsection{Soil water characteristics}

Table 1 shows the descriptive statistics for the hydrophysical properties of soil samples.Bulk density $(\mathrm{Db})$ measured in the field ranged from 0.85 to 1.08 $\mathrm{g} / \mathrm{cm}^{3}$. In general, it can be observed that minimum values of bulk density are similar in all sampled horizons, but maximum bulk density increases with depth. However, depth-averaged values show a slight increase in bulk density with depth.

This is possibly caused by the increase in the sand fraction (higher particle density) along the profile (Alvarado and Forsythe, 2005). Also farming practices, such as tillage and cropping, decrease bulk density on the surface due to the presence of roots and the addition of organic matter from pruning or soil amendments.

Table 1. Descriptive statistics for the hydrophysical soil properties analyzed for surface, subsurface and deep $(\mathrm{n}=31)$ soil horizons.

\begin{tabular}{|c|c|c|c|c|c|c|c|}
\hline Variable & Horizon & Min & Max & Mean & Median & $\begin{array}{c}\text { Standard } \\
\text { Deviation }\end{array}$ & Skewness \\
\hline \multirow[t]{3}{*}{$\mathrm{Db}\left(\mathrm{gr} \mathrm{cm}^{-3}\right)$} & Surface & 0.90 & 1.24 & 1.04 & 0.99 & 0.11 & 0.61 \\
\hline & Subsurface & 0.91 & 1.44 & 1.07 & 1.00 & 0.15 & 0.94 \\
\hline & Deep & 0.91 & 1.32 & 1.10 & 1.12 & 0.14 & 0.11 \\
\hline \multirow[t]{3}{*}{$\mathrm{FC}\left(\mathrm{m}^{3} \mathrm{~m}^{-3}\right)$} & Surface & 0.28 & 0.63 & 0.48 & 0.49 & 0.10 & -0.43 \\
\hline & Subsurface & 0.25 & 0.63 & 0.49 & 0.51 & 0.11 & -0.51 \\
\hline & Deep & 0.35 & 0.60 & 0.48 & 0.50 & 0.09 & -0.33 \\
\hline \multirow[t]{3}{*}{$\mathrm{WP}\left(\mathrm{m}^{3} \mathrm{~m}^{-3}\right)$} & Surface & 0.15 & 0.33 & 0.25 & 0.26 & 0.05 & -0.49 \\
\hline & Subsurface & 0.13 & 0.34 & 0.26 & 0.26 & 0.05 & -0.51 \\
\hline & Deep & 0.18 & 0.34 & 0.25 & 0.26 & 0.05 & -0.07 \\
\hline \multirow[t]{3}{*}{ Clay (\%) } & Surface & 13.7 & 40.5 & 25.8 & 27.6 & 8.60 & 0.07 \\
\hline & Subsurface & 7.0 & 43.4 & 24.6 & 24.1 & 10.50 & 0.03 \\
\hline & Deep & 8.0 & 32.3 & 20.3 & 21.7 & 6.70 & -0.13 \\
\hline \multirow[t]{3}{*}{ Sand (\%) } & Surface & 15.3 & 40.5 & 29.9 & 29.6 & 5.50 & -0.90 \\
\hline & Subsurface & 23.2 & 48.9 & 31.6 & 30.8 & 6.20 & 1.14 \\
\hline & Deep & 26.4 & 69.4 & 38.7 & 34.9 & 11.20 & 1.74 \\
\hline \multirow[t]{3}{*}{ Silt (\%) } & Surface & 30.0 & 58.2 & 44.2 & 43.0 & 9.00 & 0.12 \\
\hline & Subsurface & 29.6 & 64.1 & 43.7 & 44.3 & 11.20 & 0.21 \\
\hline & Deep & 19.8 & 60.8 & 41.0 & 43.4 & 11.50 & -0.32 \\
\hline $\mathrm{LA}(\mathrm{mm})$ & & 74.23 & 262.82 & 160.36 & 160.46 & 45.93 & 0.19 \\
\hline IIB $\left(\mathrm{cm} \mathrm{min} \mathrm{min}^{-1}\right)$ & & 0.01 & 0.70 & 0.16 & 0.10 & 0.18 & 2.35 \\
\hline
\end{tabular}

*Db: bulk density, FC: field capacity (water content at -0.33 MPa), WP: wilting point (water content at -1.5 MPa), LA: water layer held by the soil between FC and WP, VIb: basic infiltration velocity. Surface: 0-30 cm; subsurface: 30-60 cm; Deep: 60-90 cm. 
It is worth noting that the minimum value of $\mathrm{FC}$ in the surface layer is $0.28 \mathrm{~m}^{3} \mathrm{~m}^{-3}$, and its maximum value is $0.63 \mathrm{~m}^{3} \mathrm{~m}^{-3}$; whereas the minimum and maximum values of WP are $0.15 \mathrm{~m}^{3} \mathrm{~m}^{-3}$ and $0.33 \mathrm{~m}^{3} \mathrm{~m}^{-3}$ respectively. Thus, the minimum $\mathrm{FC}$ value overlaps the maximum WP value.

Considering both spatial distribution and depth, soils were classified into 5 structural classes: loam (L) representing $50.8 \%$ of total area; clay loam (CL) with $22.0 \%$; silt loam (SiL) with $18.6 \%$; sandy loam (SaL) with $5.1 \%$; and silty clay loam (SiCL) with $3.4 \%$. This means that even though values indicate that soils are mainly classified as loam, soil texture cannot be related with certainty to available water content when designing irrigation systems. Values are within ranges reported in Sandoval et al. (2007), Rivera et al. (2015) and Dec and Dörner (2014).

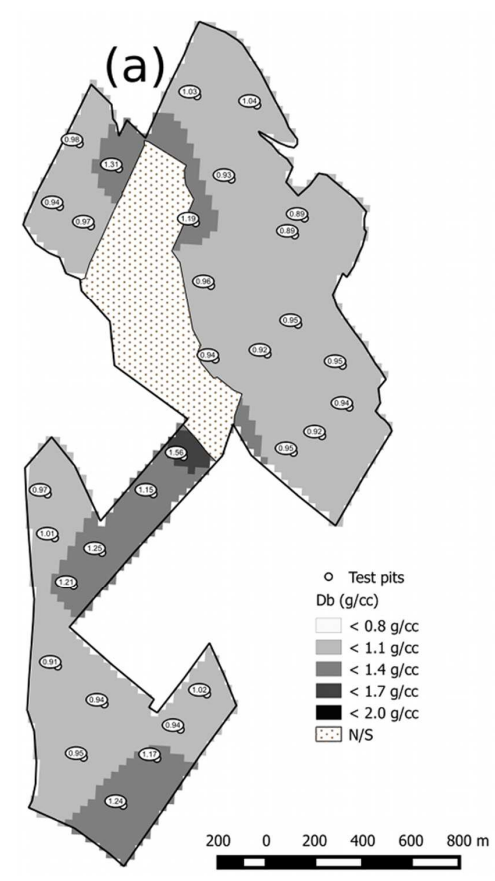

\subsection{Maps of hydrophysical soil characteristics}

Bulk density $(\mathrm{Db})$ measured in the field and spatialized using kriging (Figure 2a) shows that in the southern part of the farm, higher Db variation is observed. Opposite, the northern part of the farm shows a lower variation in bulk density. In the central part of the farm, higher bulk density is observed, reaching values above $1.4 \mathrm{~g} / \mathrm{cm}^{3}$. This area corresponds to the Arrayan series (Figure 1b). However, there is some spatial variation on bulk density that is observed on soil series maps. Thus, these areas showing discrepancies need to be considered as different for irrigation system design and management.

Figure $2 \mathrm{~b}$ shows available water content (WHC) in the first $60 \mathrm{~cm}$ of soil and spatialized using kriging.

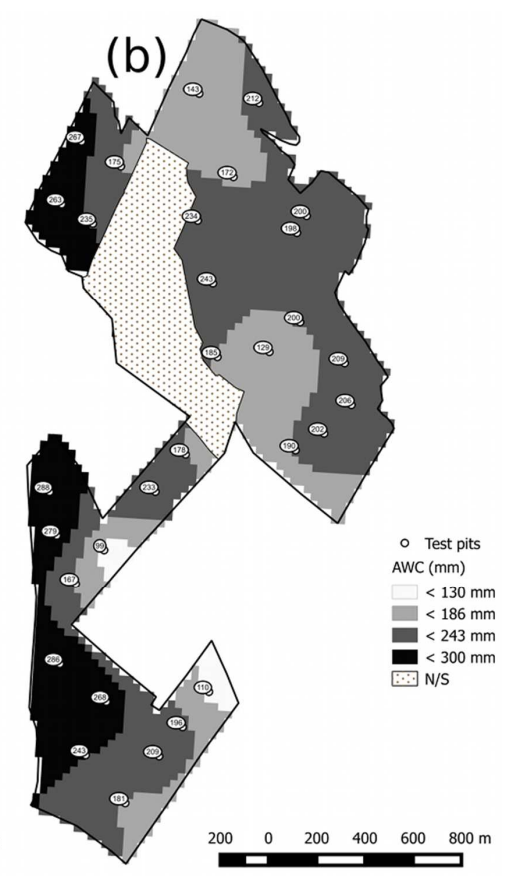

Figure 2. a) Bulk density (Db) in the surface layer and b) Soil available water content (WHC) in the surface layer. Measured values are provided for each test pit. N/S is not sampled. 
This allows us to select areas that should have differentiated management plans in the field, which is an important aspect for the design and management of irrigation systems. In general, the study area presents WHC values greater than $186 \mathrm{~mm}$. However, there are also areas where soil water content varies within the same unit, such as the southern part of the farm where WHC ranges from 100 to $300 \mathrm{~mm}$. A range of variability of $200 \mathrm{~mm}$ in WHC implies high spatial variability in soil characteristics, making the design of irrigation units more complex. The spatial variability in the field capacity and wilting point of soil in the southern part of the farm can be attributed to different soil textures, which range from loam to clay loam. Due to their morphological characteristics, Andisols absorb and retain high water content. The clay content of soils in the northern zone ranges from 30 to $40 \%$, and decreases to the south. The sand content is higher than the clay content, on average, with a slightly lower standard deviation (Table 1). Soils with the highest sand content are found in the northern and central parts of the study area, decreasing to the south and reaching values ranging from $15 \%$ to $40 \%$. Soils with the highest silt content are found in the southern part of the farm, while the lowest content was found in the northern part. Considering soil textures, silt presented the highest values for both the mean value and the standard deviation (Table 1), compared to sand and clay, and this was also observed in the deeper layers. It was also observed that in terms of depth, clay and silt mineral particles decreased, whereas sand content increased. Dörner et al. (2009) found similar values in an Andisol soil in southern Chile, reporting values ranging from $33 \%$ to $43 \%$ sand, and from $47 \%$ to $59 \%$ silt in the first $20 \mathrm{~cm}$ of soil.

\subsection{Evaluation and calibration of pedotransfer functions}

The pedotransfer function proposed by Saxton and Rawls (2006) underestimates both FC and WP (Figure $3 \mathrm{a}-3 \mathrm{~d})$. Table 2 compares the coefficients for the original model and the calibrated model. It shows that there is a shift on the relative weight of sand and clay content. In fact, the original model defines equal weights for sand and clay, while in the calibrated model the ratio of sand's and clay's weight is 100 in estimating FC and WP. However, Table 2 shows that the goodness-of-fit of both the original model, described in the equations by Saxton and Rawls (2006) (Figure 3a-3d), have a poor performance on estimating FC and WP. However, other studies indicate that the Saxton \& Rawls model is adequate for mineral soils (Hong et al., 2013). Even though calibrated coefficients were established, and there was an improvement in the model's predictive skill, still a large proportion of data (ca. 50\%) is overestimated or underestimated.

Table 3 shows the coefficients for the new pedotransfer function (Equation 7). The values of the coefficients (weights) show an important predictive skill of sand content, as well as its relationship with bulk density and organic matter. On the other hand, the least important variable is clay content. As observed in Table 2 and Figure 3e, the local calibration delivered better estimates, by decreasing RD and increasing R2 for field capacity. However, there was not a significant improvement for wilting point (Figure 3f). 

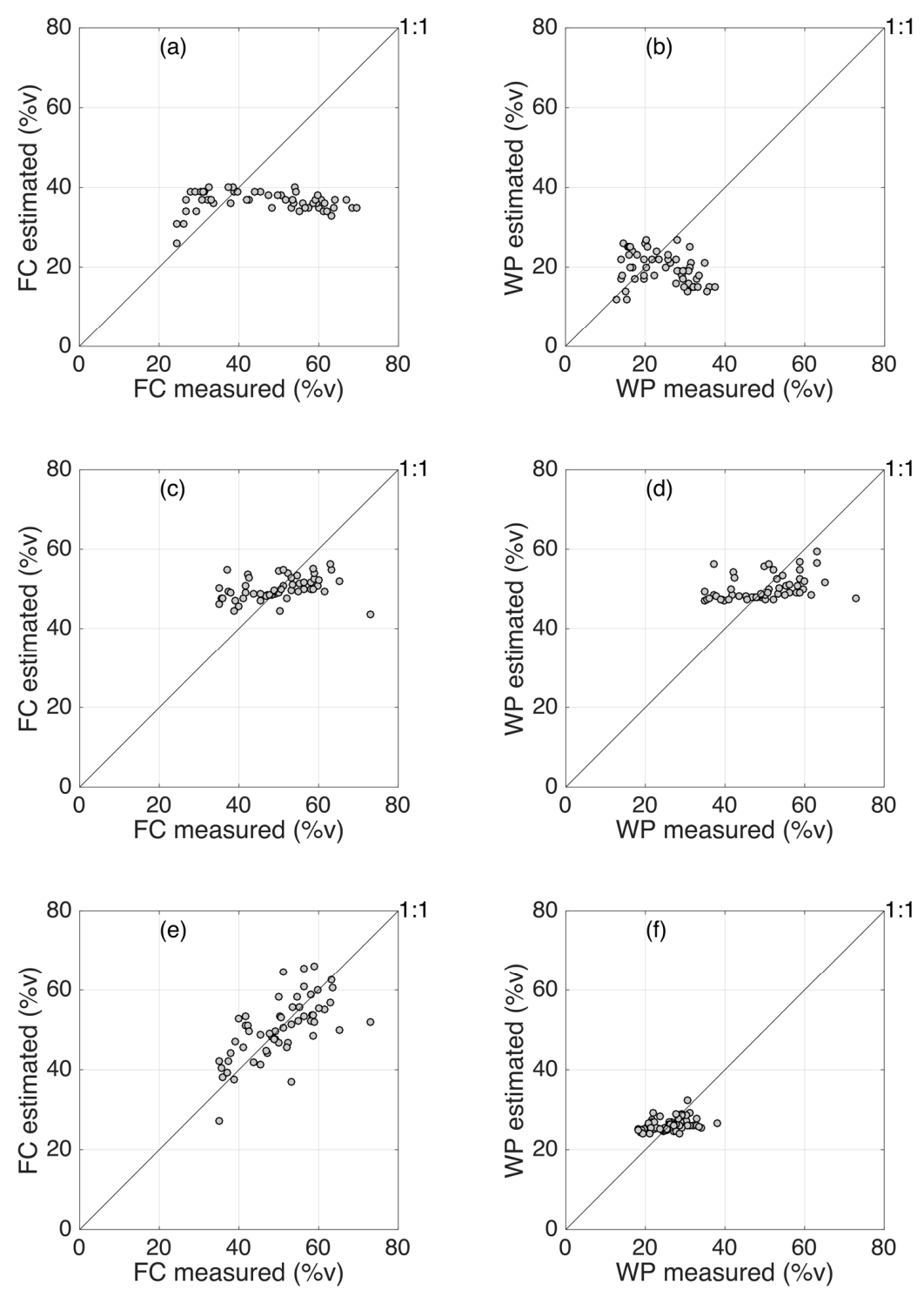

Figure 3. Measured and estimated values of water retention capacity using (a) the model 'Soil water properties' original, m3 m-3, expressed in percentage for Field capacity (FC) (b) the model 'Soil water properties' original, m3 m-3, expressed in percentage for Wilting Point (WP) (c) Measured and estimated values of water retention capacity using the model 'Soil water properties' after calibration, $\mathrm{m} 3 \mathrm{~m}-3$, expressed in percentage for field capacity (FC) (d) Measured and estimated values of water retention capacity using the model 'Soil water properties' after calibration, $\mathrm{m}^{3} \mathrm{~m}^{-3}$, expressed in percentage for Wilting Point (WP) (e) Measured and estimated values of water retention capacity using the model proposed, $\mathrm{m}^{3} \mathrm{~m}^{-3}$, expressed in percentage for field capacity (FC) (f) Measured and estimated values of water retention capacity using the model proposed, $\mathrm{m} 3 \mathrm{~m}-3$, expressed in percentage for Wilting Point (WP) 
Table 2. Goodness of fit for the original model, its calibration and proposed model to predict water content at field capacity (FC) and wilting point (WP). RMSE is $\mathrm{m}^{3} \mathrm{~m}^{-3}$ expressed in \%v.

\begin{tabular}{|c|c|c|c|c|c|c|}
\hline & & WP & & & FC & \\
\hline \multirow[t]{2}{*}{ Model } & \multirow{2}{*}{$\mathrm{R}^{2}$} & RMSE & RD & \multirow{2}{*}{$\mathrm{R}^{2}$} & RMSE & $\mathrm{RD}$ \\
\hline & & $(\% \mathrm{v})$ & $(\%)$ & & $(\% \mathrm{~V})$ & $(\%)$ \\
\hline Original & 0.058 & 10.29 & 39.17 & 0.034 & 17.33 & 34.57 \\
\hline $\begin{array}{c}\text { Calibrated } 1^{\circ} \\
\text { sol }\end{array}$ & 0.103 & 4.3 & 16.38 & 0.104 & 8.3 & 16.55 \\
\hline $\begin{array}{c}\text { Calibrated } 2^{\circ} \\
\text { sol }\end{array}$ & 0.126 & 4.25 & 16.16 & 0.121 & 8.22 & 16.39 \\
\hline \multirow{3}{*}{$\begin{array}{c}\text { Proposed } \\
\text { model }\end{array}$} & \multicolumn{3}{|c|}{ WP } & \multicolumn{3}{|c|}{$\mathrm{FC}$} \\
\hline & \multirow{2}{*}{$\mathrm{R}^{2}$} & RMSE & RD & \multirow{2}{*}{$\mathrm{R}^{2}$} & RMSE & RD \\
\hline & & $(\% \mathrm{v})$ & $(\%)$ & & $(\% \mathrm{~V})$ & $(\%)$ \\
\hline $1^{\circ} \mathrm{sol}$ & 0.104 & 6.41 & 24.39 & 0.437 & 6.88 & 13.65 \\
\hline $2^{\circ} \mathrm{sol}$ & 0.121 & 4.26 & 16.21 & 0.441 & 6.63 & 13.16 \\
\hline
\end{tabular}

$1^{\circ}$ and $2^{\circ}$ sol: $1^{\circ}$ and $2^{\circ}$ solution 
Table 3. Coefficients for the pedotransfer functions proposed*.

\begin{tabular}{ccccc}
\hline \multirow{2}{*}{ Coefficients } & \multicolumn{2}{c}{ WP } & \multicolumn{2}{c}{ FC } \\
\cline { 2 - 5 } a & $1^{\text {st }}$ sol & $2^{\text {nd }}$ sol & $1^{\text {st }}$ sol & \\
& -108.0773 & & -215.52 & \\
b & & & & \\
d & 7900 & 5926.4 & \\
e & 1.5505 & 4.5304 & \\
f & -0.8652 & & 26.5832 & \\
g & -17.9341 & & 21.9786 & \\
h & 103.8796 & & 85.9175 & \\
j & 0.0149 & & -0.378 & \\
k & -0.0202 & & -0.0263 & \\
l & -14825 & & -24829 & \\
m & 0.0079 & & 0.0051 & \\
p & 161.1144 & & 225.1538 & \\
q & -8321.4 & & -5872 & \\
r & -0.4403 & & -1.3606 & \\
t & -2.4768 & & -21.6389 & \\
A & -3.2172 & & -2.2348 & \\
B & & 0.0076 & & -0.0063 \\
C & & -0.1358 & & \\
\hline
\end{tabular}

*Correspond to the equations 6 and 7. Water content at field capacity (FC) and wilting point (WP)

\section{Discussion}

4.1. Analysis and evaluation of methods to determine homogenous soil units

Figure 4 compares the homogeneous soil units produced using the agrological approach (USDA-SAG) based on coarse data from maps and the INSITU approach, based on field measures. Analyzing bulk density and suitability of land use, no differences were found in the values of coefficient of variation. This occurs because this zone, which corresponds to soils classified as Class II, also presents a bulk density with the same spatial heterogeneity (Table 4). On the other hand, the map that compares the land use class and available water content shows differences between the two methods. The area that corresponds to class II presents a high heterogeneity (CV $=19.7 \%, \mathrm{n}=13$ ) compared to the information provided by the map of available water content distribution $(\mathrm{CV}=8.1 \%, \mathrm{n}=6)$ for the same area. Therefore, when available water content is used to differentiate different management zones, these areas would effectively be homogeneous. In general, the INSITU 
method presents more homogenous data because it can be categorized according to ranges as required (for example, soils with high, average or low soil wa ter retention capacity), to then be grouped by only one variable (WHC, Db). This does not occur in agrological studies, since soils are grouped by qualitative data.

Table 4. Mean, standard deviation (SD) and coefficient of variation (CV) of bulk density (Db) and available water content (WHC) of the soil obtained using the in situ method (ISM) y land capability class (LCC).

\begin{tabular}{ccccc}
\hline \multirow{2}{*}{ Indicator } & \multicolumn{2}{c}{ ISM } & \multicolumn{2}{c}{ LCC } \\
& $\mathrm{Db}\left(\mathrm{g} \mathrm{cm}^{-3}\right)$ & $\mathrm{WHC}(\mathrm{mm})$ & $\mathrm{Db}\left(\mathrm{g} \mathrm{cm}^{-3}\right)$ & $\mathrm{WHC}(\mathrm{mm})$ \\
\hline Mean & 0.96 & 269.5 & 0.96 & 238.6 \\
$\mathrm{SD}$ & 0.04 & 21.8 & 0.04 & 47.0 \\
$\mathrm{CV}(\%)$ & 4.16 & 8.1 & 4.16 & 19.7 \\
\hline
\end{tabular}

*For WHC, data analyzed for ISM and LCC correspond to the values obtained above $245 \mathrm{~mm}$ and class II, respectively. In addition, data of $\mathrm{Db}$ analyzed for ISM and LCC correspond to the values obtained below $1.1 \mathrm{~g} \mathrm{~cm}-3$ and class II, respectively.

\subsection{Methodological proposal}

An important parameter for design and management of micro-irrigation systems is the value of field capacity (Holzapfel et al., 2015). Thus, the pedotransfer model obtained for FC can be used for design considering this soil type. Regarding estimates of the wilting point, the model is weak in predicting this parameter (Table 2) as the model overestimates when the water content values are lower than $25 \%$, but underestimates when the values are higher than $25 \%$. In terms of the soils included in the present study, the Saxton \& Rawls model can predict some hydrophysical characteristics with an acceptable level of accuracy. These results call for more careful use of the model, as large uncertainties could appear. Similarly, the model equations were also calibrated to the local soils in a study conducted on mineral soils (Sung and Iba, 2010). The authors indicated that model calibration resulted in estimation improvement from 8 to $49 \%$. These models are only applicable to the volcanic ash type soil included in the study, and are likely to be improved in future research with other soil types. Other authors mention that it is not convenient to use pedotransfer equations in soil types different for which the model was developed (Nguyen et al 2015; Givi et al 2004). Even though the development of pedotransfer models also requires field data, our approach shows that local calibration is required to produce more accurate homogeneous soil units.

It is important to collect as much information as possible in order to have an overview of the field. The first step in a soil study for irrigation system design and management purposes is to verify soil variability by using tools such as satellite imagery, landscape analysis, previous soil studies, and borehole sampling, followed by borehole monitoring to confirm data (soil series, limitations) in order to create maps with homogeneous areas. Finally, soil samples should be collected for laboratory analysis to identify the hydrophysical properties of interest. In addition, pedotransfer functions can be also used to characterize the 
soil, provided that these functions correspond to the type of soil studied. Having analyzed the information, the maps are made with the variables either measured or estimated in the field and categorized to get an overview of the area.

\section{Conclusion}

The SAG's guidelines based on the USDA Soil Survey Manual provides qualitative data that could be used as a first step on defining homogenous soil units. The INSITU methodology describes soils from a hydrophysical point of view, which allows for characterized maps with soil quality indicators, such as clay content, bulk density and water retention capacity, which vary depending on the crop and the characteristics of the soil.

Published pedotransfer functions should be carefully assess before their use in large-scale design, as the quality the estimations depends on the data used to derive the equations. Therefore, if field data is available, we recommend calibrating equations using wellknown statistical methods such as least square. In this study, the functions obtained describe the properties of interest properly, such as the field capacity to be used in micro-irrigation, but they are likely to be improved in future research, especially those used to predict wilting point.

The maps obtained using the in situ methodology result in more homogeneous sites as measured by the coefficient of variation $(\mathrm{CV})$ values, taking a more global view that results in reducing associated costs and allows for a better use of resources. However, more research is needed to assess the reliability and replicability of produced maps, in order to define a standardized protocol to replace current practice. Also, it is necessary to investigate whether savings in energy and water offsets the cost for additional field data.

\section{Acknowledgements}

This study was funded by the Fondap Project 15130015: Water Resource Center for Agriculture and Mining. The authors would like to thank the valuable support provided in the field by Mr. Carlos Cea and the staff of the Water Resources Laboratory, Agricultural Engineering College, University of Concepción.

\section{References}

Alvarado, A., Forsythe, W. 2005. Variación de la densidad aparente en órdenes de suelo de Costa Rica. Agronomía Costarricense. 29, 85-94.

Campbell, G.S. 1974. A simple method for determining unsaturated conductivity from moisture retention data. Soil Sci. 117, 311-314.

CIREN. 1999. Descripción de materiales y símbolos. Estudio Agroecológico VIII región. Tomo 1, 288 p.

Cuevas, J., Dörner, J., Ellies, A. 2004. Elements of physics and mechanics for agricultural soils sustainability evaluation. J. Soil Sci. Plant Nutr. 4, $1-13$.

Dec, D., Dörner, J. 2014. Spatial variability of the hydraulic properties of a drip irrigated andisol under blueberries. J. Soil Sci. Plant Nutr. 14. 589-601.

Dörner, J., Dec. D., Peng, X., Horn, R. 2009. Effect of land use on structural stability and pore function of an Andisol (Typic Hapludand) in southern Chile. J. Soil Sci. Plant Nutr. 9, 190-209.

Flores, C., Holzapfel, E., Lagos, O. 2010. A dynamic decision support system for farm water management in surface irrigation: Model development and application. Chilean journal of agricultural research. 70, 278-286. 
Givi, J., Prasher, S.O., Patel, R.M. 2004. Evaluation of pedotransfer functions in predicting the soil water contents at field capacity and wilting point. Agricultural Water Management. 70, 83-96.

Gozdowski, D., Stępień, M., Samborski, S., Dobers, E.S., Szatyłowicz, J., Chormański, J. 2015. Prediction accuracy of selected spatial interpolation methods for soil texture at farm field scale. J. Soil Sci. Plant Nutr. 15, 639-650.

Gooley, L., Huang, J., Pagé, D., Triantafilis, J. 2014. Digital soil mapping of available water content using proximal and remotely sensed data. Soil use and management. 30, 139-151.

Hengl, T. 2009. A practical guide to geostatistical mapping. $2^{\circ}$ Ed. University of Amsterdam. Amsterdam, Nederland. 291 p.

Holzapfel, E., Pannuzio, A., Lorite, I., Oliveira, A., Farkas, I. 2009. Design and management of irrigation systems. Chilean Journal of Agricultural Research. 69, $17-25$.

Holzapfel, E. 2010. Manejo de agua y contaminación. In: Holzapfel, E. y J. Arumí. (Eds) Tecnología de manejo de agua para una agricultura intensiva sustentable. Editorial Universidad de Concepción. Chile. Pp: $41-71$.

Holzapfel, E., Jara, J., Coronata, A.M. 2015. Number of drip laterals and irrigation frequency on yield and exportable fruit size of highbush blueberry grown in a sandy soil. Agric. Water Manage. 148, 207-212.

Hong, S.Y., Minasny, B., Han, K.H., Kim, Y., Lee, K. 2013. Predicting and mapping soil available water capacity in Korea. PeerJ. 1, e71.

Iqbal, J., Thomasson, J., Jenkins, J., Owens, P., Whisler, F. 2005. Spatial variability analysis of Soil Physical Properties of Alluvial Soils. Soil Sci. Soc. Am. J. 69, 1338-1350.

Jury, W., Gardner, W.R., Gardner, W.H. 1991. Soil Physics. 5th ed. John Wiley \& Sons, New York.
Nguyen, P.M., Van K., Le, Y., Botula, D., Cornelis, W.M. 2015. Evaluation of soil water pedotransfer functions for Vietnamese Mekong Delta soils. Agricultural Water Management. 158, 126- 138.

NRCS. 2008. Bulk Density. Natural Resources Conservation Service of the United States Department of Agriculture. Washington, United States. Available at http://www.nrcs.usda.gov/Internet/ FSE_DOCUMENTS/nrcs142p2_053256.p

Rabbi, S., Roy, B., Miah, M., Amin, M., Khandakar, T. 2014. Spatial variability of physical soil quality index of an agricultural field. Applied and environmental soil science. 379012, 1-10.

Reynolds, W., Yang, X., Drury, C., Zhang, T., Tan, C. 2003. Effects of selected conditioners and tillage on the physical quality of a clay loam soil. Canadian Journal of Soil Science. 83, 381- 393.

Rivera, D., Sandoval, M., Godoy, A. 2015. Exploring soil databases: a self-organizing map approach. Soil Use and Management. 31, 121-131.

SAG. 2001. Pauta para estudios de suelo. División de Protección de los Recursos Naturales Renovables. Servicio Agrícola y Ganadero. MINAGRI. Santiago, Chile. 21p.

Sandoval, M., Stolpe, N., Zagal, E., Mardones, M. 2007. The effect of crop-pasture rotacions on the $\mathrm{C}, \mathrm{N}$ and $\mathrm{S}$ contents of soil aggregates and structural stability in a volcanic soil of south-central Chile. Acta Agriculturae Scandinavica Section B-Soil and Plant Science. 57, 255-262.

Sandoval, M., Dörner, J., Seguel, O., Cuevas, J., Rivera, D. 2012. Métodos de análisis físicos de suelos. Publicación $N^{\circ}$ 5. Departamento de Suelos y Recursos Naturales, Universidad de Concepción. Chillán, Chile.

Santis, G. 2005. Mapa de reconocimiento de los suelos de la Región del Bio Bio (Sector Norte). Tesis Ing. Agr. Univ. de Chile. Fac. De Ciencias Agronómicas. Chile. $84 \mathrm{p}$. 
Saxton, K., Rawls, W. 2006. Soil water characteristics estimates by texture and organic matter for hydrologic solutions. Soil Sci. Soc. Am. J. 70, 1569-1578.

Selles, G., Ferreyra, R., Ruiz, R., Ferreyra, R., Ahumada, R. 2012. Compactación de suelos y su control. Estudio de casos en el Valle de Aconcagua. Boletín INIA No 234. Instituto de Investigaciones Agropecuarias, Centro Regional de Investigación La Platina. Santiago, Chile. 53p.

Soil Survey Division Staff. 1993. Soil survey manual. Soil Conservation Service. U.S. Department of Agriculture Handbook 18, Washington, DC, USA.

Sung, C., Iba, J. 2010. Accuracy of the Saxton-Rawls method for estimating the soil water characteristics for mineral soils of Malaysia. Pertanika J. Trop. Agric. Sci. 33, 297-302.
USDA - Soil Survey Staff. 2009. Soil Taxonomic. A basic system of soil classification for making and interpreting soil surveys. U.S. of Department of Agriculture, Natural Resources Conservation Service. $2^{\circ}$ ed. Washington D.C. $871 \mathrm{p}$.

Van Genuchten, M.Th. 1980. A closed-from equation for predicting the hydraulic conductivity of unsaturated soils. Soil Sci. Soc. Am. J. 44, 892-898.

Wösten, J.H.M., Pachepsky, Y., Rawls, W.J. 2001. Pedotransfer functions: bridging the gap between available basic soil data and missing soil hydraulic characteristics. Journal of Hydrology. 251, 123-150. 